\title{
A Performance-based Approach for Fire Safety Engineering: a Comprehensive Engineering Risk Analysis Methodology, a Computer Model, and a Case Study
}

\author{
M.K. MATHEWS, D.M. KARYDAS and M.A. DELICHATSIOS \\ Factory Mutual Research Corporation \\ Norwood, MA 02062 USA
}

\begin{abstract}
This paper presents a systematic approach for fire safety engineering, utilizing risk analysis principles. The described methodology is the foundation for a computer program developed for the performance-based fire risk assessment of buildings and the evaluation of alternative safety systems that may maintain the risk of building occupants and equipment, in respect to fire hazards, at tolerable levels. The computer program evaluates fire risk of a specified facility by automatically (1) generating an event tree and enumerating all credible accident scenarios that may follow a range of initiating events, (2) assessing of resulting consequences and associated impact, and (3) calculating the corresponding likelihood of occurrence of each accident scenario. This methodology and the corresponding computer program comprise modeled physical phenomena and stochastic characteristics associated with each elemental event of a scenario. A case study is presented wherein various strategies of risk reduction are compared by implementation of this technique and by deployment of the developed computer tool.
\end{abstract}

KEYWORDS: Fire Risk Assessment, Event Tree, Smoke Damage, Deterministic Models, Probabilistic Models, Emergency Response

\section{BACKGROUND}

Fire safety standards have been traditionally developed on the basis of engineering principles addressing countermeasures against deviations from normality. Their implementation involves specification solutions tested by experience and experimentation of small or large scale. By the nature of their development and acceptance, such standards address the worst or typical case scenarios. As experience with catastrophic event like fire is limited and as large amount of testing for combinations of parameters controlling preventive and protective measures is prohibitively expensive, prescriptive methods result in extreme conservatism without flexibility in finding alternative solutions of satisfactory effectiveness. Moreover, this approach usually addresses individual components of the protected system. It does not identify interactions of individual elements having desirable or sometimes undesirable consequences making the worst-case scenario design a misleading concept. 
Recognizing the limitations of specification-based fire standards, efforts in individual countries, e.g., the USA ${ }^{1,23}$, Australia ${ }^{4}$, New Zealand ${ }^{5,6}$, Canada ${ }^{7}, \mathrm{Japan}^{8}, \mathrm{UK}^{9}$, Scandinavia ${ }^{10}$, and within international organizations, e.g., $\mathrm{ISO}^{11,12}, \mathrm{CIB}^{13}$, are being directed toward establishing performance-based practices and standards using quantified risk as the basic performance parameter. The objective of these efforts is to establish a consistent and widely acceptable methodology to evaluate total system risks and propose alternative solutions that reduce risk to tolerable levels.

Risk Assessment models adapted within the scope of the aforementioned initiatives are characterized by many common elements ${ }^{14}$. They include deterministic and non-deterministic models to simulate hazardous situations and their likelihood of occurrence, along with events, when safety and control systems or system components operate successfully or fail. They also consider the resulting consequences and quantified impact. This approach helps to understand the uncertainties and sensitivities of different components involved.

The benefits of the performance-based approach using quantified risk as the performance parameter of safety and control systems can be summarized in the following list:

- examination and evaluation of existing standards and practices with respect to their consistency and cost effectiveness,

- identification of alternative solutions with equivalent performance at a lower cost,

- flexibility in the design of alternative solutions with equal risk reduction,

- optimization of protection and control systems in terms of maximization of effectiveness at reduced cost, and

- identification and prioritization of areas introducing uncertainties, therefore, requiring further research efforts.

The increasing power of computers makes the transition from specification-based to performancebased standards easier to achieve. Computer based tools are being developed to measure the performance of a facility in confronting the risk associated with various catastrophes and accidents. Property damages and life-threatening impacts are the major concerns. There are several computer programs to model fire, its growth and spread and the resulting damage. Some of these methods combine the fire development and mitigation along with their probability of occurrence and thus the associated risk. Since several types of fire accidents are possible, each having several possibilities of development, while a variety of prevention and mitigation methods may be deployed, different tools combine these numerous possibilities in different ways. HAZARD $\mathrm{I}^{15}$, one of the earliest in this category, simulates only one scenario at a time and evaluates the corresponding consequence. CRISP $^{16}$, is an object oriented software developed in UK for deterministic simulation of fire hazards used with a Monte Carlo sampling technique, to incorporate stochastic characteristics. The risk assessment model developed at $\mathrm{NRCC}^{17}$ starts with several possible pre-assigned design fires and their probability, simulates the fires for the designed fire growth and control and then for the selected scenarios, evaluates the consequences, the impact and the associated risk.. FRESCO, the software presented in this paper, computes fire risk for a facility by automatically generating an event tree analysis of all credible scenarios for a range of initiating fires, for specified engineered control and mitigation systems, including ventilation and for human factor response. Property damage is the impact measure used by the software, while other tools are focusing on life safety. The software, at present, is verified only for fires in a Telephone Central Office (TCO) and is used for one compartment at a time, 
although the underlying deterministic modeling part of the software can handle flashover conditions and smoke transport in several rooms and several floors. While a simple evacuation model based on time needed to escape is available, the software currently addresses property damage specifically caused by corrosive combustion products and soot. The modular structure of the software makes it easy to enhance or simplify its component models or add additional models for improvement and verification as necessary. As a performance measuring tool, it can evaluate risk for various fire mitigating strategies easily.

\section{THE METHODOLOGY}

When a fire starts many possible scenarios could develop. These scenarios are generated by events that correspond to the characteristics of the fire, the fire prevention and protection systems of the facility, the type of ventilation and smoke management available and the response of the local fire department. The present computer program generates an event tree of all credible accident scenarios, each with its probability of occurrence and the resulting consequence at the end of the scenario. Each scenario is characterized by a sequence of events corresponding to success or failure of engineered systems or human responses. Figure 1 outlines the data flow and algorithms used in this computation process.

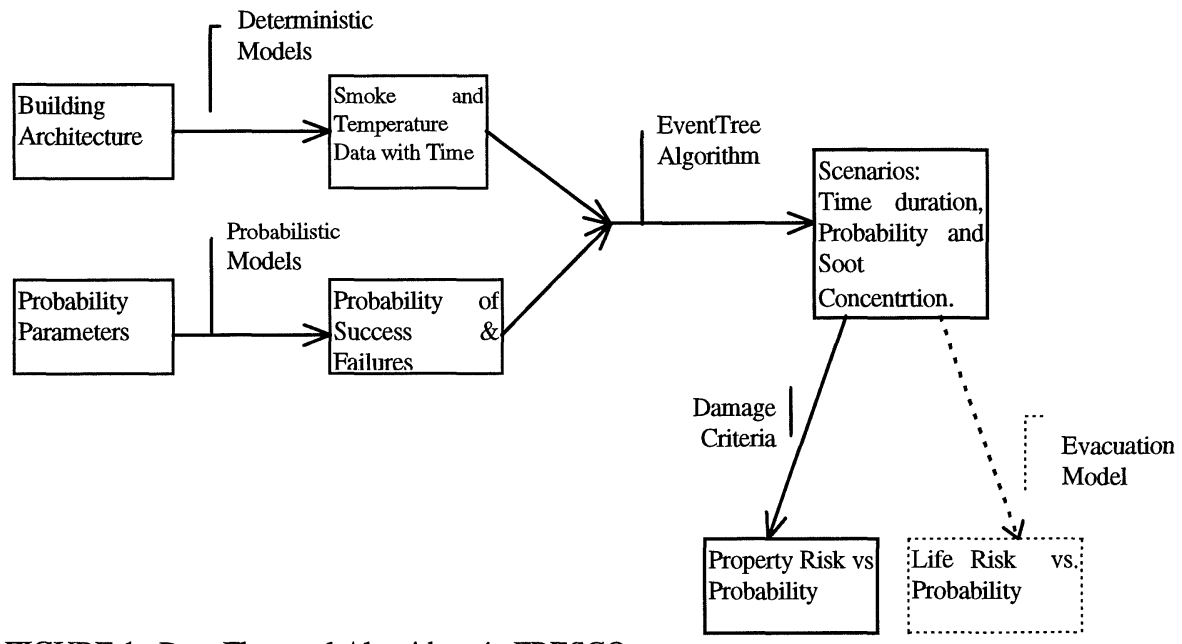

FIGURE 1. Data Flow and Algorithms in FRESCO

The user-friendly interface of FRESCO accepts information on building geometry, construction, fire controlling devices and human response factors. Deterministic models are used to predict fire growth and smoke transport with respect to time for all possible initiating fires and conditions such as ventilations. Using this information, the event tree algorithm examines all combinations of events for each credible scenario, its likelihood of occurrence, its completion time, accumulated soot on a typical surface and the corresponding impact. A list of scenarios as well as risk curves showing probability versus consequence are given as outputs. 


\section{Major Characteristics}

Engineered Systems and Corresponding Events. A facility can be engineered with the following systems to prevent, control and reduce damage from possible fires. These systems are (1) room ventilation, (2) automatic detection systems, (3) mechanisms for shutting down ventilation upon fire detection, (4) smoke management systems and (5) automatic protection systems. In addition, depending on whether the fire occurs during business hours or non-business hours, (6) manual detection, (7) emergency response and (8) intervention by the local fire department are also considered. Events are defined by activation or non-activation of the engineered systems (i.e., automatic detection) and success or failure of each mitigating function (for example, response of an emergency team or the local fire department). A sequence of such events forms a scenario. A database with reliability data for several brands and kinds of engineered systems is used with the software.

Deterministic Models. A number of documented deterministic computer models exist, many of them developed by Factory Mutual Research Corporation (FMRC), to simulate fire development ${ }^{18,19}$, smoke generation and transport $\mathrm{t}^{20}$, automatic detection, and soot deposition. In these models, temperature and smoke concentrations and other combustion products from a fire are computed with respect to time and location. All deterministic models used at present are zone models (e.g., BRI $2^{20}$ ); however, the modular structure of the software makes it easy to use a field model if needed. Input data includes geometric parameters (compartment size, fuel location, detection location, openings), environmental parameters indoors and outdoors (e.g., temperature, humidity, ventilation) and flammability properties of materials.

The type of ventilation and the corresponding air circulation are major factors in determining the concentration of smoke. For a scenario in which air circulation is present at a rate larger than a specified value, a well-mixed model is used to compute smoke concentration from a fire; when no ventilation and no mixing are present, a two-layer zone model is used. Once the smoke concentration is found over a time, the deposition of soot is computed in two ways. The first option is to use a simplified expression assuming a single particle size for soot and gravitational deposition. Because this is a reasonable general assumption, this option is used as a default. The second option is to use a detailed procedure accounting for variability of particle size and the predominant mechanisms of particle deposition on room surfaces, including vulnerable surfaces of sensitive equipment. The time required for detection is also computed similarly, using either a two-layer zone model (BRI2) or a fire-ceiling jet ${ }^{21}$ model for detection.

Probabilistic Models. Each scenario consists of several events. Each event of any scenario is characterized by a specific probability of occurrence. Component events in a scenario are assumed to be independent of each other and, therefore, the probability of a scenario can be found as a product of the probabilities of its independent component events. Probabilities of success or failure for engineered systems are found using reliability data available or utilizing appropriate reliability models (e.g., fault trees and Markov models), while probability distributions of different human responses are found from facility specific inquiries.

Damage Criteria. In a Telephone Central Office facility, a serious concern is damage from small fires, that can cause damaging soot deposition on electronic equipment. This damage has been quantified as a function of soot deposition ${ }^{3}$. The deposition of soot on a surface is calculated from the concentration of smoke in the surrounding air, its deposition velocity and the duration of time the surface is exposed to such smoke. A deposition of 30 micrograms (sq. $\mathrm{cm}$ ) or more is 
assumed to cause significant damage ${ }^{22}$. Deterministic models compute soot deposition and smoke concentration as functions of time for prescribed fires.

Risk Estimation. Each scenario is characterized by a specific probability of occurrence. Each component event of a scenario determines the duration of exposure of vulnerable equipment to a certain concentration of soot. Therefore, for each scenario the amount of soot deposition can be estimated. Using corresponding damage criteria for soot deposition, damage (i.e., smoke impact) is estimated. Risk corresponding to a scenario is presented as the vector of its probability and the resulting impact.

Type of Fire. Three fire sizes, $60 \mathrm{~kW}, 100 \mathrm{~kW}$, and $400 \mathrm{~kW}$ are selected, each with equal likelihood of occurrence. These fire sizes represent the most likely fire sources in a TCO environment based on extensive analysis of real accidents ${ }^{23}$, FMRC experiments ${ }^{24}$, and fire growth and spread models. For a conservative estimation of damage, each fire is considered to last for two hours, if no mitigation is applied.

\section{Events Activation/Success}

We discuss in this section how the engineered systems and human responses are accounted for in the present methodology and computer program.

Detection. Most of the facilities are equipped with automatic detection systems. In addition, manual detection is possible, whenever people are present, which in turn depends on whether events occur during business hours or non-business hours. Automatic detection occurs, when air temperature and smoke concentration reach a level, specified by the type of detector. Detection times are found using deterministic simulation models. Manual detection time is assumed to follow a probability distribution (defined by average, minimum and maximum time). From this distribution, the manual detection time and its probability of occurrence are calculated. Automatic detection could occur before or after manual detection. Whichever detection mode happens earlier, is accounted by the program first and, if it is successful the other detection mode is not considered. If the earlier one fails, the other detection mode is considered by the algorithm.

Ventilation. Almost all Telephone Central Office locations have high ventilation rates (20 to 80 volume changes per hour). As long as the existing ventilation is working, smoke concentration is computed using a well-mixed model, assuming that smoke concentration is the same throughout the room. If the existing ventilation system is not working because of malfunction, a two-layer model is used to compute the smoke concentration and temperature of the upper and lower layers of the enclosure.

Ventilation Shut Down/Smoke Management. Many facilities are designed such that ventilation shuts down automatically or manually at fire detection. After the ventilation is shut down, a twolayer model is used to compute the smoke concentration and air temperature. Some facilities are equipped with a smoke management system, which activates upon detection of a fire, effectively changing the mixing rate of ventilation. In such a case, a well-mixed model is used in the present program for computation using increased mixing and ventilation rates after detection.

Emergency Organization. After detection, depending on the facility and on the time of day, (i.e., business or non-business hours), the emergency organization of the facility becomes active. An 
assigned person in the emergency group may notify the fire department, while the members of the group may try to put out the fire. In some facilities the notification of the fire department may be done by the automatic detection systems. If fire starts during non business hours and the members of the emergency group are not present at the facility, these activities may be delayed due to the time needed for travel and notification. In such a case, the local fire department may respond before the emergency organization. Response time is defined as the time required to extinguish the fire and clean the room air from smoke. The response time of the Emergency Organization is assumed to follow a probability distribution where parameters of the distribution are specified for business and non business hours. Having a response time before a specified amount of soot deposition is considered as a success, while a response time after a significant amount of deposition is defined as a failure of the Emergency Organization response.

Fire Department. The fire department is notified either by the emergency organization or by the detection system, depending on the facility and the time of the incident. The response time of the fire department is assumed to follow a distribution with specified parameters. If the fire department is notified by the emergency organization, the response time of the fire department is dependent on the response time of the emergency organization; they are independent of each other if the notification is done by the detection systems. Having a response time before a specified amount of soot deposition is considered a success, while a response time after a significant amount of deposition is defined a failure of the fire department response.

Automatic Protection. Halon and smoke management systems are the most common systems in Telephone Central Offices. Automatic sprinklers and dry chemicals may be used in some rooms. Halon and dry chemical systems are assumed to be activated by the detection systems, while sprinklers are activated by the surrounding air temperature. The computation of protection success probability depends on the specific systems available in each site.

\section{A CASE STUDY}

Risk assessment was performed for a site using FRESCO based on the following installation and engineered systems such as detection, protection and others.

\section{EXISTING CONDITIONS:}

1) Undivided room of size $71 \mathrm{~m} \times 58 \mathrm{~m} \times 3.4 \mathrm{~m}$ (high).

2) Continuously ( $24 \mathrm{hrs}$.) operated and manned room with valuable equipment (e.g., computers).

3) Low ventilation rate, approximately 3 volume changes per hour (with probability of working being 0.95 and probability of shutting down at fire detection being 0.83 ).

4) No specific smoke management system.

5) Standard automatic detectors according to NFPA 72-E standards ( sensitive to 5 deg. C rise in temperature and with 0.059 failures per year).

6) Automatic protection system using Halon (FM 200) ${ }^{25}$.

7) Low fuel load (fire sizes as in a TCO).

Observations and Considerations. People in the room may detect fires and such detection was assumed to occur in five minutes with $90 \%$ probability. After fire detection, use of Halon (or more precisely FM 200) or Emergency/Fire Department response is assumed to extinguish the fire. Emergency organization may put off the fire in 3-8 minutes after detection and the fire 
department may put it off in 6-12 minutes after notification both with about $75 \%$ probability. The existing ventilation system is switched off upon smoke detection.

To ensure continuity of operation of this facility, one consideration was to divide the room into two identical subdivisions. The value of the undivided room was $\$ 200$ million, the value of the each subdivision, if divided, was to be $\$ 100$ million dollars. The frequency of fire initiation for this facility was taken as $0.0018 / y^{2}$ ar $^{23}$. The following analysis, using the present procedure, evaluates various alternatives for reducing the risk exposure including space subdivision.

\section{EVALUATION OF ALTERNATIVES INCLUDING SPACE SUBDIVISION}

A summary of the quantitative analysis done for the design alternatives including room space subdivision, new sensitive/aspirator detectors and a special smoke management system, for this site is given in Table 1. A condensed set of scenarios used in the analysis and generated for the "Base" case (existing state without automatic protection) and for the case with an aspirator detection system is shown in Table 2. A part of the generated event tree is given in Figure 2. Figure 3 shows the risk curves for three cases namely the Base case, the existing room with an aspirator detection system and the existing room with aspiration detection system combined with a smoke management system (described below). The results of this analysis are the following:

1) In evaluating smoke damage conditions, it was found that existing automatic detectors may not normally activate for small to medium fires due to the large size room.

2) Subdivision will reduce proportionally the total damage at any time of effective fire extinguishment. A fire can be detected faster by any automatic detection system in a smaller room. The likelihood of both subdivisions having fire at the same time is assumed to be negligible.

3) Sensitive/(Aspirator) detectors (sensitive to a temperature rise of $2.7 \mathrm{deg}$. C with 0.002 failures per year) installed with or without sub-division will assure early detection.

4) An FM 200 protection system activated by sensitive/(aspirator) detectors will further reduce damage. Special design considerations have to be made for reducing false alarms.

5) A special smoke management system that activates upon detection, a secondary air handling unit of high reliability (0.98) capable of removing smoke with a ventilation rate of at least 10 volume changes per hour while supplementing with at least $10 \%$ fresh air, will reduce smoke deposition, as well as aid in evacuation and fire fighting.

\section{CONCLUSION}

A tool, with a user-friendly interface and attached property databases has been developed. This tool can simulate fire scenarios and evaluate damage impact and the corresponding probability. With the help of this tool, risk reduction strategies are evaluated and compared for a few facilities with valuable equipment.

The major features of the present development that distinguish it from other similar efforts are:

1) Deterministic and probabilistic models are separated and their outputs are available prior to evaluating event tree paths.

2) An automated event tree algorithm has been developed that reduces the calculation time considerably and also provides Risk Curves (probabilities vs. impact, see Figure 3). 
Smoke Risk

Analysis

\begin{tabular}{|c|c|c|c|c|c|c|c|}
\hline \multirow{2}{*}{$\begin{array}{l}\text { Protection } \\
\text { Strategy }\end{array}$} & \multicolumn{2}{|c|}{$\begin{array}{l}\text { BIG ROOM } \\
\text { Value : } \$ 200 \\
\text { million }\end{array}$} & \multirow[b]{2}{*}{$\begin{array}{c}\text { Reduction } \\
\text { due } \\
\text { Strategy }\end{array}$} & \multicolumn{2}{|c|}{$\begin{array}{l}\text { Two Half } \\
\text { Rooms } \\
\text { Value: } \$ 100 \\
\text { million each }\end{array}$} & & \multirow{2}{*}{$\begin{array}{c}\text { Reduction } \\
\text { Factor } \\
\text { due to Division }\end{array}$} \\
\hline & $\begin{array}{c}\text { Risk } \\
\text { million/yr }\end{array}$ & $\begin{array}{l}\text { Loss } \\
\text { million }\end{array}$ & & $\begin{array}{c}\text { Risk } \\
\text { million/yr }\end{array}$ & $\begin{array}{l}\text { Loss } \\
\text { million }\end{array}$ & $\begin{array}{l}\text { Reduction } \\
\text { due } \\
\text { Strategy }\end{array}$ & \\
\hline Base & 0.016 & $\$ 8.89$ & 1.00 & 0.0074 & $\$ 4.11$ & 1.00 & 2.16 \\
\hline Smoke Mgt & 0.0046 & $\$ 2.56$ & 3.48 & 0.0027 & $\$ 1.50$ & 2.74 & 1.70 \\
\hline Halon & 0.0056 & $\$ 3.11$ & 2.86 & 0.0032 & $\$ 1.78$ & 2.31 & 1.75 \\
\hline Aspirator Detection & 0.012 & $\$ 6.67$ & 1.33 & 0.0065 & $\$ 3.61$ & 1.14 & 1.85 \\
\hline New Det \& Sm.Mgt & 0.00011 & $\$ 0.06$ & 141.59 & 7.4E-05 & $\$ 0.04$ & 100.00 & 1.53 \\
\hline New Det \& Halon & 0.00117 & $\$ 0.65$ & 13.72 & 0.00065 & $\$ 0.36$ & 11.40 & 1.80 \\
\hline $\begin{array}{l}\text { New Det, Halon, } \\
\text { SmMgt }\end{array}$ & 8.1E-05 & $\$ 0.04$ & 198.51 & $6 \mathrm{E}-05$ & $\$ 0.03$ & 124.37 & 1.35 \\
\hline
\end{tabular}

where:

Base refers to a benchmark case which has no fire protection, but has all other parameters as in the existing situation of the computer room.

Risk

million/year

is, the expected loss in million dollars per year.

Loss (million) is the average loss (in millions) of a fire accident.

Reduction Due is Reduction in loss amount due to by implementing a protection

To Strategy strategy and comparing it to the base case, i.e.,

(Base Loss)/(Strategy Loss).

Reduction Factor is Reduction in Loss amount by subdividing the room, keeping the due to subdivision same protection strategy, i.e,

(Loss in Big Room)/(Loss with two rooms keeping same protection Strategy).

Aspirator Detection is for using a better Detection by a highly reliable and very sensitve detection system.

New Det \& Sm.Mgt is for using the secondary air handling unit smoke management system along with the better detection system as above.

New Det \& Halon is for having Halon (FM 200) protection along with the better detection system as above. 


\begin{tabular}{|c|c|c|c|c|}
\hline \begin{tabular}{|l} 
Fire \\
Initiatiion
\end{tabular} & \begin{tabular}{|c|} 
Ventilation \\
On
\end{tabular} & $\begin{array}{l}\text { Detection } \\
\text { Condition }\end{array}$ & $\begin{array}{l}\text { Automatic } \\
\text { Detection }\end{array}$ & $\begin{array}{l}\text { Manual } \\
\text { Detection }\end{array}$ \\
\hline
\end{tabular}
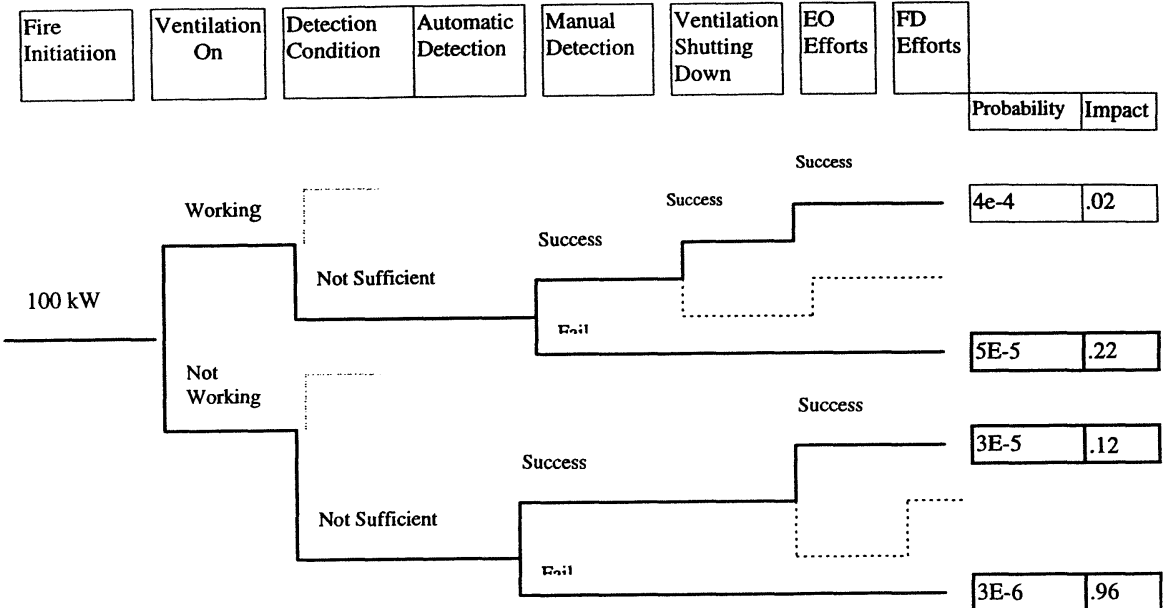

FIGURE 2. A Part of the Generated Event Tree for BASE Case

\section{Risk for Different Strategies}

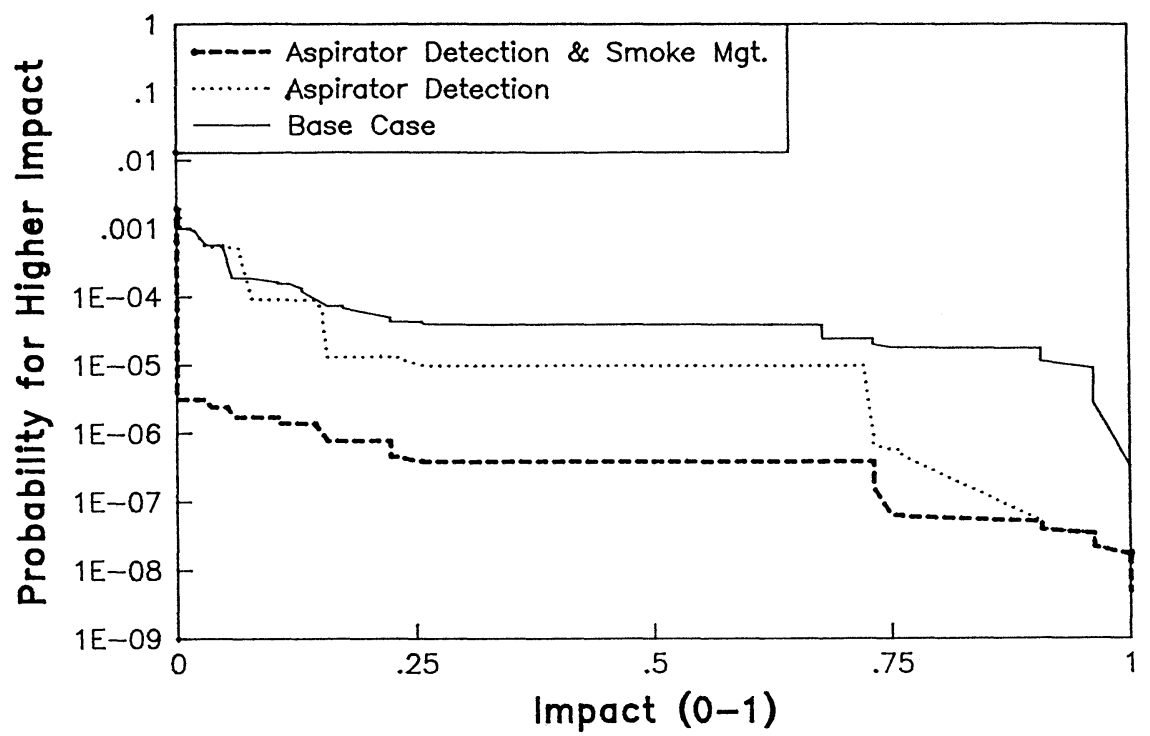

FIGURE 3. Risk Curves. 


\begin{tabular}{rrlrrr} 
No. & $\begin{array}{c}\text { Fire } \\
\text { Type }\end{array}$ & \multicolumn{1}{c}{$\begin{array}{c}\text { Scenario } \\
\text { (Combination of Events) }\end{array}$} & $\begin{array}{c}\text { Probability } \\
(0-1)\end{array}$ & $\begin{array}{c}\text { Time } \\
(\mathrm{s})\end{array}$ & $\begin{array}{c}\text { Impact } \\
(0-1)\end{array}$ \\
1 & $400 \mathrm{~kW}$ & FR,NN,CY,DN,MN & $1.15 \mathrm{E}-07$ & 7200 & 1.00 \\
2 & $100 \mathrm{~kW}$ & FR,NN,CN,MN & $3.00 \mathrm{E}-06$ & 7200 & 0.962 \\
3 & $60 \mathrm{~kW}$ & FR,NN,CN,MN & $3.00 \mathrm{E}-06$ & 7200 & 0.907 \\
4 & $400 \mathrm{~kW}$ & FR,NN,CY,DY,EN,FN & $6.29 \mathrm{E}-07$ & 1611 & 0.758 \\
5 & $400 \mathrm{~kW}$ & FR,NY,CY,DN,MN & $2.18 \mathrm{E}-06$ & 7200 & 0.731 \\
6 & $400 \mathrm{~kW}$ & FR,NY,CY,DY,VY,EN,FN & $1.40 \mathrm{E}-05$ & 1598 & 0.678 \\
7 & $400 \mathrm{~kW}$ & FR,NY,CY,DN,MY,VY,EN,FN & $7.98 \mathrm{E}-07$ & 1586 & 0.635 \\
8 & $400 \mathrm{~kW}$ & FR,NN,CY,DN,MY,EY & $8.26 \mathrm{E}-07$ & 653 & 0.259 \\
9 & $400 \mathrm{~kW}$ & FR,NN,CY,DY,EN,FY & $3.30 \mathrm{E}-06$ & 649 & 0.256 \\
10 & $100 \mathrm{~kW}$ & FR,NY,CN,MN & $4.68 \mathrm{E}-05$ & 7200 & 0.223 \\
11 & $400 \mathrm{~kW}$ & FR,NN,CY,DY,EY & $2.49 \mathrm{E}-05$ & 539 & 0.173 \\
12 & $400 \mathrm{~kW}$ & FR,NY,CY,DY,VY,EN,FY & $5.89 \mathrm{E}-05$ & 697 & 0.131 \\
13 & $100 \mathrm{~kW}$ & FR,NN,CN,MY,EY & $2.68 \mathrm{E}-05$ & 772 & 0.118 \\
14 & $400 \mathrm{~kW}$ & FR,NY,CY,DN,MY,VY,EN,FY & $2.46 \mathrm{E}-06$ & 758 & 0.108 \\
15 & $60 \mathrm{~kW}$ & FR,NY,CN,MN & $4.68 \mathrm{E}-05$ & 7200 & 0.106 \\
16 & $60 \mathrm{~kW}$ & FR,NN,CN,MY,EY & $2.70 \mathrm{E}-05$ & 778 & 0.079 \\
17 & $400 \mathrm{~kW}$ & FR,NY,CY,DY,VY,EY & $3.82 \mathrm{E}-04$ & 589 & 0.049 \\
18 & $100 \mathrm{~kW}$ & FR,NY,CN,MY,VY,EY & $4.23 \mathrm{E}-04$ & 772 & 0.019 \\
19 & $60 \mathrm{~kW}$ & FR,NY,CN,MY,VY,EY & $4.25 \mathrm{E}-04$ & 778 & 0.004 \\
20 & & & & &
\end{tabular}

\begin{tabular}{|c|c|c|c|c|}
\hline $\begin{array}{l}\text { Fire } \\
\text { Type }\end{array}$ & $\begin{array}{c}\text { Scenario } \\
\text { (Combination of Events) }\end{array}$ & $\begin{array}{l}\text { Probability } \\
(0-1)\end{array}$ & $\begin{array}{c}\text { Time } \\
(s)\end{array}$ & $\begin{array}{l}\text { Impact } \\
(0-1)\end{array}$ \\
\hline $400 \mathrm{~kW}$ & $\mathrm{FR}, \mathrm{NN}, \mathrm{CY}, \mathrm{DN}, \mathrm{MN}$ & $6.00 \mathrm{E}-09$ & 7200 & 1.00 \\
\hline $100 \mathrm{~kW}$ & $\mathrm{FR}, \mathrm{NN}, \mathrm{CY}, \mathrm{DN}, \mathrm{MN}$ & $6.00 \mathrm{E}-09$ & 7200 & 0.962 \\
\hline $60 \mathrm{~kW}$ & FR,NN,CY,DN,MN & $6.00 \mathrm{E}-09$ & 7200 & 0.907 \\
\hline $400 \mathrm{~kW}$ & $F R, N N, C Y, D Y, E N, F N$ & $5.14 \mathrm{E}-07$ & 1622 & 0.761 \\
\hline $400 \mathrm{~kW}$ & $\mathrm{FR}, \mathrm{NY}, \mathrm{CY}, \mathrm{DN}, \mathrm{MN}$ & 1.14E-07 & 7200 & 0.731 \\
\hline $400 \mathrm{~kW}$ & $F R, N Y, C Y, D Y, V Y, E N, F N$ & 8.69E-06 & 1618 & 0.722 \\
\hline $400 \mathrm{~kW}$ & $F R, N Y, C Y, D N, M Y, V Y, E N, F N$ & 4.17E-08 & 1586 & 0.635 \\
\hline $400 \mathrm{~kW}$ & $\mathrm{FR}, \mathrm{NN}, \mathrm{CY}, \mathrm{DN}, \mathrm{MY}, \mathrm{EY}$ & 4.32E-08 & 653 & 0.259 \\
\hline $400 \mathrm{~kW}$ & FR,NN,CY,DY,EN,FY & $3.12 \mathrm{E}-06$ & 615 & 0.231 \\
\hline $100 \mathrm{~kW}$ & $\mathrm{FR}, \mathrm{NY}, \mathrm{CY}, \mathrm{MN}, \mathrm{DN}$ & $1.14 \mathrm{E}-07$ & 7200 & 0.223 \\
\hline $400 \mathrm{~kW}$ & $F R, N Y, C Y, D Y, V Y, E N, F Y$ & $5.06 \mathrm{E}-05$ & 625 & 0.152 \\
\hline $400 \mathrm{~kW}$ & $F R, N N, C Y, D Y, E Y$ & 2.63E-05 & 503 & 0.145 \\
\hline $400 \mathrm{~kW}$ & $\mathrm{FR}, \mathrm{NY}, \mathrm{CY}, \mathrm{DN}, \mathrm{MY}, \mathrm{VY}, \mathrm{EN}, \mathrm{FY}$ & $1.29 \mathrm{E}-07$ & 758 & 0.108 \\
\hline $60 \mathrm{~kW}$ & $\mathrm{FR}, \mathrm{NY}, \mathrm{CY}, \mathrm{MN}, \mathrm{DN}$ & $1.14 \mathrm{E}-07$ & 7200 & 0.106 \\
\hline $400 \mathrm{~kW}$ & $\mathrm{FR}, \mathrm{NY}, \mathrm{CY}, \mathrm{DY}, \mathrm{VY}, \mathrm{EY}$ & $4.13 \mathrm{E}-04$ & 514 & 0.066 \\
\hline $100 \mathrm{~kW}$ & $F R, N N, C Y, D Y, E Y$ & $2.97 \mathrm{E}-05$ & 574 & 0.053 \\
\hline $60 \mathrm{~kW}$ & $F R, N N, C Y, D Y, E Y$ & $2.99 \mathrm{E}-05$ & 588 & 0.029 \\
\hline $100 \mathrm{~kW}$ & $F R, N Y, C Y, M Y, V Y, E Y$ & 4.23E-04 & 772 & 0.019 \\
\hline $100 \mathrm{~kW}$ & $F R, N Y, C Y, M N, D Y, V Y, E Y$ & 4.68E-05 & 930 & 0.018 \\
\hline $60 \mathrm{~kW}$ & $F R, N Y, C Y, M Y, V Y, E Y$ & 4.25E-04 & 778 & 0.004 \\
\hline
\end{tabular}

FR - Fire Ignition occurs

NY - Ventilation working well

$\mathrm{NN}$ - Ventilation is not working

$\mathrm{CY}$ - Condition to detect exist

$\mathrm{CN}$ - Detection condition does not exist

DY-Automatic detection Occurs

DN -Auto Detection Fails
Event Explanations:

\section{Explanations}

MY - Human Detection Occurs

MN - Muman detection fails

VY - Ventilation shuts down

$V N$ - Ventilation fails to shut down

EY - Emergency Organization puts down fire

EN - Emergency Organization Fails

FY - Fire department puts down fire

FN - Fire department fails to put down fire
Time - Time duration of the scenario in seconds Maximum time considered is two hours

Impact - Value lost per Value at risk

Risk - (Impact, Probability of the scenario)

Probability - Frequency per year

Example: Scenario \#8, FR,NN,CY,DN,MY,EY; Ignition occurs (FR) when regular ventilation is not working (NN),

sufficient condition for detection exists (CY), automatic detection fails (DN), but people detect fire(MY) and the EO succeeds in putting off the fire (EY). 
3) Fire Spread and growth models are part of the deterministic models for simple geometry.

Future developments are pursued in the following areas:

1) Extension of the numerical code for application to multi-room occupancies.

2) Development of a methodology to calculate uncertainties (model, parameters and other) in an efficient way.

3) Further validation of component sub models and especially the fire spread and fire growth models.

\section{REFERENCES}

1. Bukowski, R.W., Babrauskas, V., "Developing Rational, Performance-based Fire Safety Requirements in the Model Building Codes" Fire and Materials, Vol. 18, 173-191 (1994).

2. Snell, J., Babrauskas, V., Fowell, A.D., "Elements of a Framework for Fire Safety Engineering,” Interflam ‘93, Interscience Communication Ltd., London, UK, p. 447, 1993.

3. Karydas D.M., "A Probabilistic Methodology for The Fire and Smoke Hazard Analysis of Electronic Equipment,” Interflam '93, Interscience Communication Ltd., London, UK, 1993.

4. Microeconomic Reform: Fire Regulation, An explanatory document describing developments leading to more effective Regulations for Fire Safety, National Building Fire Safety Systems Project of the Building Regulation Review Task Force, Department of Industry, Technology, and Commerce, Sidney, Australia, May 1991.

5. Buchanan, Andrew H., "Fire Engineering for a Performance Based Code," Interflam '93, Interscience Communication Ltd., London, UK, p. 457, 1993.

6. Building Act 1991, (No. 150), New Zealand Government, Welington, 1991.

7. Yung, D., Beck, V.R., "A Risk-Cost Assessment Model for Evaluating Fire Risks and Protection Costs in Apartment Buildings," Proceedings of the International Symposium of Fire Engineering for the Building Structures and Safety, Melbourne, Australia, pp. 15-1914-15, November 1989.

8. Tanaka, Takeyoshi, "The Concept of A Performance-based Design Method for Building Fire Safety," Proceedings of the 11th UJNR Panel on Fire Research and Safety, San Francisco, CA, 1989.

9. BSI Standards, Panel FSM/-/5- and Technical Committee FSM/24- "Fire Safety, Draft Code of Practice for the Application of Fire Safety Engineering Principles to Fire Safety in Buildings," London, UK, June 1994.

10. Magnusson, Sven Erik, "Performance Based Codes," Interflam '93, Interscience Communication Ltd., London, UK, p. 413, 1993.

11. ISO 6241, "Performance Standards in Buildings-Principles for their Preparation and Factors to Be Considered;"' International Organization for Standardization, Geneva, 1984.

12. ISO DIS 7162, "Performance Standards in Buildings-Contents and Format of Standards for Evaluation of Performance," International Organization for Standardization, Geneva, 1984.

13. Publication 64, "Working with the Performance Approach in Buildings," Conseil International du Batiment, Rotterdam, Netherlands, 1982.

14. Hall J.R., "Key Distinctions in and Essential Elements of Fire Risk Analysis," Fire Safety Science-Proceedings of the Third International Symposium, p. 467, Borehamwood, UK, 1991.

15. Peacock R.D. and Bukowski R.W., "A Prototype Methodology for Fire Hazard Analysis," Fire Technology, p. 15, February 1990. 
16. Fraser-Mitchell J.N., "An Object-Oriented Simulation (Crisp II) for Fire Risk Assessment," Fire Safety Science Proceedings of the Fourth International Symposium, Ottawa, 1994.

17. Beck V.R. \& Yung D., "The Development of a Risk-Cost Assessment Model for the Evaluation of Fire Safety in Buildings," Fire Safety Science Proceedings of the Fourth International Symposium, Ottawa, 1994.

18. Delichatsios, M.M., Mathews, M.K., and Delichatsios, M.A., "An Upward Fire Spread and Growth Simulation," Fire Safety Science: Proceedings of the Third International Symposium, p. 207, Elsevier, NY, 1991

19. Mathews, M K, Delichatsios, M.M, Delichatsios, M.A., Alpert, R.A., "Fire Spread and Growth, a Computer Simulation," Fire Safety Science, an International Journal, University of Science and Technology of China Press, Hefei, China, Vol. 2, No. 1, March 1993.

20. Yamada, S., Tanaka, T., "A Model for Predicting Concentrations of Carbon Monoxide in Building Fires," Fire Safety Science-Proceedings of the Fourth International Symposium, p. 539, 1994.

21. Yu, H-Z., Stavrianidis, P., "The Transient Ceiling Flows of Growing Rack Storage Fires," Fire Safety Science-Proceedings of the Third International Symposium, p. 281, Borehamwood, UK, 1991.

22. Karydas, D.M., "Smoke Damage Criteria of Electronic Equipment," Technical Report, Factory Mutual Research, Project No. 92-09, April 1994.

23. Network Reliability: A Report to the Nation. Compendium of Papers, Presented by the Federal Communications Commission's Network Reliability Council, National Engineering Consortium, Chicago, June 1993.

24. Hill J.P., Chaffee J.L., Chu F.L., Karydas D.M., Tewarson A.T., "Investigation of Passive Fire Protection for Telephone Central Office Cable Trays," FMRC Technical Report 0R6R1.RR, May 1993, Factory Mutual Research Corporation, Norwood, MA.

25. Metchis, K., "The Regulation of Halon and Halon Substitutes," Proceedings of the Halon Options Technical Working Conference 1994, pp. 7-30, The University of New Mexico, New Mexico Engineering Research Institute, Center for Global Environmental Technologies, Albuquerque, NM, May 1994.

26. Liebesman B.S., Tortella M., "Reliability of a Class of Telephone Switching Systems," IEEE 1982, Reliability and Maintainability (annual) Symposium. 